\title{
Research on Thermal Reflection and Cooling Curing Coating Material of Nano Modified Emulsified Asphalt for Urban Road Pavement
}

\author{
Yongqiang Zhong, ${ }^{1, *}$ \\ ${ }^{1}$ Transportation College, Huaiyin Institute of Technology, Huai'an, 223003, China
}

\begin{abstract}
Based on the development of thermal reflective coating materials at home and abroad, modified emulsified asphalt was selected as the substrate material and nano TiO2 was selected as the filler. Different filler dosage was selected, the optimal ratio of thermal reflective coating was obtained by analyzing the pavement temperature data measured in the field experiment. Finally, the construction technology of pavement thermal reflection coating material is described in detail.
\end{abstract}

\section{Introduction}

In the hot summer months, the sun's intensity is high and the asphalt concrete absorbs a lot of the sun's heat, which makes the road temperature much higher than the air temperature people feel. Therefore, there are two problems: 1) the extremely high road temperature reduces the carrying capacity of the road and rut disease occurs on the asphalt pavement under the repeated rolling of vehicles; 2) The extremely high road temperature makes the urban "heat island effect" more serious [1-2].

Due to the generally high temperature in recent years, there is often a continuous drought and high temperature in summer which has not been encountered in decades. The continuous high temperature is easy to cause rutting of asphalt pavement. In order to prevent the formation of urban road rut, a preventive heat reflection cooling coating material is studied to protect the road rut and reduce the heat island effect at the same time, especially in the field of bus stop and urban intersection. The nano modified emulsified asphalt coating has the obvious advantages of good cooling effect, quick preparation, convenient construction, moderate price, good combination of road modified emulsified asphalt material with the original road surface and preventive maintenance function of anti-seepage sealing and joint sealing [3-4].

\section{Brief introduction of nano modified materials}

Nanomaterials refer to particles with particle size between $1 \mathrm{~nm}$ and $100 \mathrm{~nm}$. When a material reaches the nanoscale, it will have a series of effects that make the nanomaterial have unique physical properties such as hardness, refractive index and chemical properties such as anti-aging, photocatalysis, etc. Nanomaterials are widely used in construction, especially as coatings, but the use and research of nanomaterials in roads are very little. Nanomaterial technology has developed rapidly in recent years, the application of nanomaterials in the field of transportation will be more and more in the future[5-6].

Nano $\mathrm{TiO}_{2}$ is commonly known as titanium dioxide. Nano $\mathrm{TiO}_{2}$ is white powder in appearance and has many excellent properties such as resistance to bacteria, anti-ultraviolet, anti-aging, photocatalysis, etc. Therefore, $\mathrm{TiO}_{2}$ is widely used, among which the most common sunscreen in people's life is also added with nano $\mathrm{TiO}_{2}$. It is used in coating, paint, plastic and many other fields. The main reason for choosing nano $\mathrm{TiO}_{2}$ is its ultraviolet protection function. Nano- $\mathrm{TiO}_{2}$ can reflect or scatter ultraviolet light. So it is a kind of ultraviolet protection agent with superior performance .

\section{Design and preparation of nano modified emulsified asphalt coating materials}

Firstly, the type of matrix material and filler of thermal reflection coating material are determined. Modified emulsified asphalt is used as the matrix material of thermal reflection coating because of its good wear resistance, high temperature stability, construction workability. The coating filler is nano $\mathrm{TiO}_{2}$, which has good anti-ultraviolet performance and thermal reflection performance. The temperature reduction effect of the filler on the thermal reflection coating material is analyzed by testing respectively. As the result, nano $\mathrm{TiO}_{2}$ has excellent performance in reflecting solar rays and the proportion of each component will also have a certain impact on the cooling performance of the coating

*Email: zyqjlu@126.com 
material. The higher the dosage, the higher the cost. The filler may not be completely combined with the matrix material. The dosage of nano $\mathrm{TiO}_{2}$ was selected as $0 \%$, $1.0 \%, 2.0 \%, 4 \%$ respectively and $4 \%$ was taken as its maximum.

The preparation method and steps of nano modified emulsified asphalt thermal reflection coating are as follows:

1) Weighing modified emulsified asphalt and nano $\mathrm{TiO}_{2}$ filler with corresponding quality;

2) Add filler to the modified emulsified asphalt and stir it at a high speed for $5 \mathrm{~min}$ with a stirring instrument until it is uniform;

3) After mixing, put the coating into spray container;

4) Natural curing at room temperature after spraying.

\section{Cooling effect test of nano modified emulsified asphalt coating material}

In the summer of extremely high temperature, the energy generated by the sun irradiation on asphalt concrete pavement makes the temperature of asphalt pavement rise sharply, and its surface temperature can reach $63^{\circ} \mathrm{C}$ or even exceed $63^{\circ} \mathrm{C}$ [7-8]. So far, there are two ways to reduce road temperature. One way is for road maintenance workers to sprinkle water on the road regularly and the other way is to increase the reflectivity of the road. The first way of sprinkling water is the most commonly used, but a symptom is not a cure. The second way to improve the reflectivity of the road is permanent cure.

Field test method for cooling effect of thermal reflection coating of emulsified asphalt modified by nano- $\mathrm{TiO}_{2}$ is as follows:

1) Preparation of thermal reflection coating. The matrix materials modified emulsified asphalt and nano $\mathrm{TiO}_{2}$ with corresponding quality are weighed with an

Table 1. Temperature table of thermal reflection coating of emulsified asphalt mixed with nano $\mathrm{TiO} 2$ at various times

\begin{tabular}{|c|c|c|c|c|c|}
\hline Time & $\begin{array}{c}\text { Uncoated asphalt } \\
\text { pavement } \\
/{ }^{\circ} \mathrm{C}\end{array}$ & $\begin{array}{c}\text { Nano } \mathrm{TiO}_{2} \\
\text { content } 0 \% \\
/{ }^{\circ} \mathrm{C}\end{array}$ & $\begin{array}{c}\text { Nano } \mathrm{TiO}_{2} \\
\text { content } 1.0 \% \\
/{ }^{\circ} \mathrm{C}\end{array}$ & $\begin{array}{c}\text { Nano } \mathrm{TiO}_{2} \\
\text { content } 2.0 \% \\
/{ }^{\circ} \mathrm{C}\end{array}$ & $\begin{array}{c}\text { Nano } \mathrm{TiO}_{2} \\
\text { content } 4.0 \% \\
/{ }^{\circ} \mathrm{C}\end{array}$ \\
\hline $12: 00$ & 43.1 & 42.5 & 40.6 & 39.2 & 38.3 \\
\hline $12: 15$ & 44.2 & 43.7 & 41.8 & 40.4 & 39.4 \\
\hline $12: 30$ & 45.5 & 44.8 & 42.5 & 41.3 & 40.2 \\
\hline $12: 45$ & 46.7 & 45.7 & 43.3 & 42.1 & 40.9 \\
\hline $13: 00$ & 47.8 & 46.9 & 44.1 & 42.7 & 41.5 \\
\hline $13: 15$ & 48.6 & 47.7 & 44.7 & 43.3 & 42.1 \\
\hline $13: 30$ & 49.7 & 48.6 & 45.4 & 43.9 & 42.8 \\
\hline $13: 45$ & 50.5 & 49.4 & 45.9 & 44.5 & 43.5 \\
\hline 14:00 & 51.2 & 50.3 & 46.3 & 44.9 & 43.8 \\
\hline
\end{tabular}

electronic scale and the two materials are placed in a beaker and fully stirred with an instrument. The heated reflective coating is put into a spray container and cured naturally at room temperature for $12 \mathrm{~h}$.

2) Select the site and spraying area. From the perspective of experimental safety and road quality, the spraying area of $30 \mathrm{~cm} \times 30 \mathrm{~cm}$ is selected on the road section with fewer motor vehicles and high road quality.

3) Select 4 pieces of $30 \mathrm{~cm} \times 30 \mathrm{~cm}$ area, and ensure that the 4 pieces are completely exposed to the sun. Sprays nano-modified emulsified asphalt thermal reflection coating with different mixing amount in the 4 pieces and pay attention to keep the spraying uniform and the sprayed thermal reflection coating should completely cover the asphalt surface, as shown in Figure 1 .

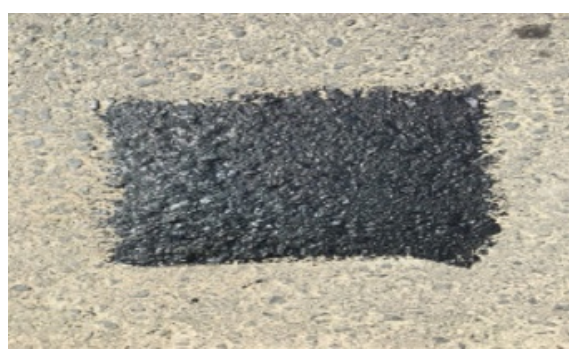

Figure 1. Thermal reflection coating of emulsified asphalt mixed with nano $\mathrm{TiO}_{2}$

In order to fully reflect the cooling effect of the thermal reflection coating, a day with temperature above $30^{\circ} \mathrm{C}$ was selected according to the weather in Huai 'an City in May and the test time was from 12:00 p.m. to 14:00 p.m. The temperature of the asphalt pavement sprayed with overheated reflective coating was measured every $15 \mathrm{~min}$ and the temperature was measured with a temperature measuring gun. The experimental data were recorded, as shown in Table 1. 


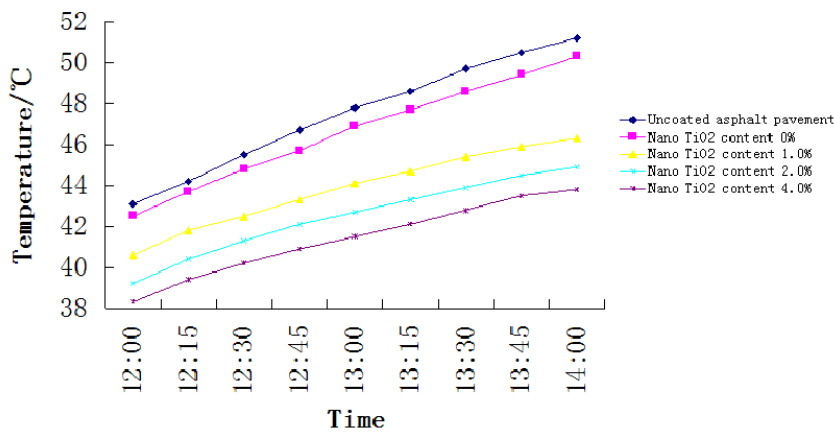

Figure 2. Temperature curves of thermal reflection coating of emulsified asphalt mixed with nano $\mathrm{TiO}_{2}$ at various times

It can be seen from Table 1 and Figure 2 that the greater the proportion of nano $\mathrm{TiO}_{2}$ is added, the greater the road temperature will be reduced. When the incorporation of nano $\mathrm{TiO}_{2}$ ratio is $4 \%$, the road surface temperature reduction is the most. $11.9 \mathrm{~g}$ of nano- $\mathrm{TiO}_{2}$ was needed to lay a thermal reflection coating of $1 \mathrm{~m}^{2}$. $1 \mathrm{~kg} \mathrm{Nano} \mathrm{TiO}_{2}$ is about 200-500 yuan. Foundation brush one square metre of emulsified asphalt the price is $2.2 \mathrm{~kg} / \mathrm{m}^{2}$ to $2.5 \mathrm{~kg} / \mathrm{m}^{2}$. Modified emulsified asphalt price is 5 yuan $/ \mathrm{kg}$ to 8 yuan $/ \mathrm{kg}$. Therefore, after comprehensive consideration, the optimal incorporation ratio of nano $\mathrm{TiO}_{2}$ thermal reflective coating is $4 \%$ and the maximum reduction of road temperature is $7.4^{\circ} \mathrm{C}$.

\section{Construction technology of pavement thermal reflection coating material}

\subsection{Basic requirements for thermal reflection coating construction}

\subsubsection{Requirements of thermal reflection coating on original road surface}

Thermal reflective coating technology can not only reduce the temperature of the road surface and prevent water from leaking into the roadbed, but also can repair the road surface of minor damage. In order to ensure that the pavement quality requirements are met after construction, the original pavement needs to meet the following requirements: 1) the original pavement has enough strength and stiffness; 2) The original road surface maintains good overall stability; 3 ) The original road surface must be smooth and clean.

\subsubsection{Weather requirements of thermal reflection coating}

The morphology of modified emulsified asphalt is viscous. If the temperature is too high, the modified emulsified asphalt will continue to soften and is not easy to dry. If the temperature is too low, it will increase the difficulty of material transportation, storage and construction. The temperature of construction should be above $10^{\circ} \mathrm{C}$ and below $35^{\circ} \mathrm{C}$.Construction should be avoided in rainy days or water on the road is not dry.

\subsection{Construction process}

The following introduces the construction process of the coating. First of all, the road surface to be coated with thermal reflection coating should be cleaned. The prepared thermal reflection coating should be poured into the asphalt sprinkler and then the sprinkler should be used for construction. The aggregate should be sprinkled through the spreader and finally the roller should be used for rolling to meet the standard.

1) The construction unit sent people to contact the traffic management organization, the road section to be constructed shall be controlled. Put the corresponding traffic signs and the signs should be clear at a mile.

2) The optimal period of bonding with thermal reflective coating should be considered for new asphalt pavement. When applying heat reflective coating on old asphalt pavement, it is necessary to pay attention to the situation that there is no oil pollution on the pavement. If there is, it must be dealt with. In addition, if the pavement structural strength problems should be repaired in time, these operations are to ensure the quality of construction. The morphology of modified emulsified asphalt is viscous. If the temperature is too high, the modified emulsified asphalt will continue to soften and is not easy to dry. If the temperature is too low, it will increase the difficulty of material transportation, storage and construction. The temperature of construction is above $10^{\circ} \mathrm{C}$ and below $35^{\circ} \mathrm{C}$. In addition, construction should be avoided in rainy days.

3) After the completion of Step 2), the road surface of the construction section needs to be pretreated. The newly built pavement surface has less debris and can be cleaned properly, but there are many debris such as dust on the old road surface, then the blower can be used to blow the debris to the roadside.

4) The road surface needs to be cleaned and the construction machinery and equipment should be prepared. The hardening time is greatly affected by temperature, so the dosage of adding hardening agent should be moderate.

5) The best ratio of thermal reflective coating is determined through experiment. Spraying or rolling coating can be adopted for coating. If the area of thermal reflective coating is large, spraying is the best choice. If the thermal reflection coating area is relatively small, roller coating can be selected. 
6) After the thermal reflective coating is coated, the skid resistance of the thermal reflective coating is lower than that of the normal road surface. So it is necessary to lay a layer of anti-skid aggregate on the coating and keep in good health. When road is strong enough, traffic can resume.

\section{Conclusion}

By adding nano $\mathrm{TiO}_{2}$ in different proportions into modified emulsified asphalt, the cooling performance of the heat-reflecting coating is different. The more nano- $\mathrm{TiO}_{2}$ is added, the better the cooling effect of the heat-reflecting coating will be. Considering the cost and the good combination of the filler and the matrix material, the maximum dosage is $4 \%$, which can reduce the road temperature by $7.4^{\circ} \mathrm{C}$ at most.

\section{References}

1. Xu Yongxiang, Li Yunde, Shi Hua, Yang Zhenbo, Feng Yong. Research Progress of Solar Thermal Reflection Thermal Insulation Coatings [J]. Paint \& Coatings Industry, 2010(01).

2. Liang Manjie. Research on photothermal effect mechanism and thermal reflection coating technology of asphalt pavement [D]. Harbin: Harbin Institute of Technology Road and Railway Engineering Master Thesis, 2006.

3. Zhang Fangfang. Research on rutting resistance of asphalt mixture [D]. Master Dissertation of Xi 'an University, 2004:1-4.

4. Kinouchi, T, Yoshinaka, T., Fukae, N., Kanda, M. Development of cool pavement with dark colored high albedo coating[C]. Fifth Conference for the Urban Environment, 2004.

5. Wan, W.C., Hien, WN., Ping, T.P., Aloysius, A.J.W. Study on the effectiveness of heat mitigating pavement coatings in Singapore[C]. Second International Conference on Countermeasures to Urban Heat Islands, Berkeley, California, 2009.

6. Wang Wei, Cao Xuejuan, Tang Boming. Application of solar thermal reflection coating in asphalt pavement [J]. Highway \& Automotive Transportation, 2010:97-99.

7. Zhang Xin. Research on cooling mechanism and application of thermal reflection and thermal resistance technology for asphalt pavement [D]. Harbin: Road and Railway Engineering Doctoral Dissertation of Harbin Institute of Technology, 2011.

8. Zheng Mulian, He Litao, Gao Xun, Wang Fei, Cheng Cheng. Performance analysis of thermal reflection coating for asphalt pavement based on cooling function [J]. Journal of Traffic and Transportation Engineering, 2013, (05). 